\title{
Blended Learning Model Trough Kanji Hyoushi App On Shokyuu Hyouki Class
}

\author{
Dini Maulia ${ }^{1}$, Darni Enzimar Putri ${ }^{2}$ \\ \{dinimaulia86@gmail.com ${ }^{1}$, enzi.sajefib.unand@gmail.com² \\ 1,2 Japanesse Department, Faculty of Humanities, Universitas Andalas, Padang, Indonesia
}

\begin{abstract}
Shokyuu Hyouki is a compulsory subject that is given to third-semester students on Japanese Department Andalas University. The main purpose of Shokyuu Hyouki course is to improve student's capability in understanding Kanji suited to N4. This research is part of a descriptive study classified as true experimental, it explains the application of Blended learning method on Shokyuu Hyouki subject. As a learning method, Blended learning combines lecture and online class model at the same time by adding Kanji Hyoushi app as media. The result shows that the practice of Blended learning model in Shokyuu Hyouki subject has been successful. It is shown on the increasing percentage of students whose marks are ranged from $\mathrm{A}$ to $\mathrm{B}+$. Through observation and interview, the finding shows that Blended learning model helps the students in mastering Kanji at ease.
\end{abstract}

Keywords: Kanji, Shokyuu Hyouki, Blended learning.

\section{Introduction}

Shokyuu Hyouki subject (JPG 202) is a compulsory course that is given to the secondsemester students on Japanese Department Andalas University. It is a continuation course of Hyouki Nyuumon in which Hyouki means "to write" and Nyuumon defies as "continuation". This subject is mainly designed to improve student's capability in writing Japanese Kanji, but the overall purposes of this subject are:

1. To improve student competence in reading and writing advance Kanji letter on N4 level

2. To improve student capability in understanding and writing texts in the Japanese language

3. To work upon student skill in translating the written text from Japanese to Indonesia language or otherwise.

Shokyuu Hyouki that is designed on Japanese Language and Literature Study which is later called as Japanese Department was previously named as Hyouki II. The name of the subject is replaced as the result of curriculum alteration to KKNI standard. The shifting is not only done toward the name of the course but also on the achievement targets that should be attained by the students who take this course, the details of the target achievements are listed as follow:

1. Students can read and write in Kanji on N4 level 
2. Students understand texts that are written in the Japanese language

3. Students have the ability to write in the Japanese language

4. Students can also translate a written text from Japanese to Indonesia language or otherwise

5. Students should improve their competence in both soft skills (such as independence, critical and analytic thinking) and intrapersonal skill (includes integrity, discipline, hard work, politeness/ ethic/moral value, and confidence)

As a compulsory subject, Shokyuu Hyouki supports other compulsory courses, among them, Sakubun I (writing composition), Shokyuu Nihongo (advance Japanese language) and translation. In addition, this course is also a supplementary course for other classes such as Dokkai (Japanese Text Reading), Correspondence in Japanese, and Goiron (comprehensive study on Japanese words). These subjects are crucial in understanding the general concept of the Japanese language, because student skill in the Japanese should not only be measured orally but also written.

Kanji is Japanese letters that are adapted from Chinese culture, the basic form of the letters come from drawing in which one letter represents more than one meanings, and these letters were introduced to Japan since the first century ${ }^{1}$. At least 2000 Kanji letters should be memorized in order to fluent in Japanese, and it also takes time to master the Japanese Kanji ${ }^{2}$. Moreover, the university trains each student to meet the general standard which is stated on the national curriculum of the Japanese language. It is written that the bachelor graduates from Japanese department must master 650 Kanji for the least which is on a par to N3 (the Japanese language levels consist of 5 general tiers in which $\mathrm{N} 1$ is regarded as the highest standard and $\mathrm{N} 5$ is placed as the lowest competency level). While the class was previously conducted as Hyoki II before it is changed into Shokyuu Hyouki, students only had to memorize 200 Kanji letters. The limitation of this subject lies in its teaching method as the entire class was held as lecture while the materials and modules were finite and not varied; while in attaining N4 level, students must remember at least 300 letters. Each student must study 100 more letters to pass N4, it also means that to reach level N3 students must memorize 200 more Kanji letters. To pass $\mathrm{N} 3$ is one general requirement to achieve the KKNI standard, so this model of learning (Hyouki II) is no longer suitable with the target achievement on KKNI curriculum.

As consequence, learning method in mastering Kanji should be changed, difficult materials and monotonous teaching method which are regarded as the main cause for the student's failure should be replaced; so Hyouki II is later introduced as an advance model of learning which is named as Shokyuu Hyouki. This article tries to explain the application of blended learning method which is implemented on Shokyuu Hyouki class. This model is a collaboration of traditional teaching model or face to face meeting and a modern class model which is also known as daring ${ }^{3}$ or online class in which Kanji Hyoushi app is used as the main media for this course.

The main purpose of this research is to find the new method that is suitable with Shokyuu Hyouki that is also applicable to blended learning model with the addition of Kanji Hyoushi app as media. While the merit of the study is as a reference learning model on Shokyuu Hyouki subject through the application of blended learning model. 


\section{Methods}

This research is a descriptive study to explain the current phenomena through the application of the scholarly procedure in answering the question with actual ${ }^{4}$ approach. This research is part of true experimental study, it compares tests result from different groups ${ }^{5}$. It tries to compare the test result on students from different benches (2017 and 2018). The final marks for subject Hyouki II and Shokyuu Hyouki are compared one another to measure the level of success on blended learning model.

The subject of this research is the university students on their second semester at Japanese Department Andalas Univesity (bench 2018). The design of this research is the application of blended learning model on Shokyuu Hyouki course with Kanji Hyoushi app as media. In previous years, Shokyuu Hyouki classes had been conducted through Teacher-Centered Learning. While this research tries to implement a blended learning model with Kanji Hyoushi app as the main media in Shokyuu Hyouki. This research is part of class behavior study, as lecturer monitors the implementation of blended learning model on Shokyuu Hyouki class, it should be noted that Shokyuu Hyouki course is only done within the classroom only.

\section{Research Procedure \\ Planning}

The implementation of blended learning model with the help of Kanji Hyoushi app on Shokyuu Hyouki course is started with RPS (semester learning program) construction plan. To draft the RPS as the first procedure in preparing the class is served as the significant point in conducting this research. During this phase, RPS should be discussed by team-teaching before the new teaching model is implemented to Shokyuu Hyouki course. Choosing Kanji Hyoushi is also done, although there are several possible applications that can be implemented, team teaching decided to choose one specific app. The purpose of this app is to help the student to focus on their study and support them to pass UKBJ (Japanese language competency exam); later, JLPT N1-N5 Japanese Test is chosen as the possible test option.

\section{Action and Implementation of the Model}

Shokyuu Hyouki is taught by two different lectures, each lecturer must complete 8 meetings on both classes. The first lecture is responsible for the first meeting to the midsemester examination (UTS) through lecture class model. It is designed to compare student competence in mastering Japanese Kanji in the different learning model. On the first meeting, RPS of Shokyuu Hyouki course is introduced to the students, during this meeting the lecture will explain the student contracts and learning model that are implemented for all 16 meetings.

Since the standard achievement on this class is difficult, student discipline in completing the assignments on class or as take-home assessment is arranged within the student contract, and it plays a significant role for the final mark. Detail explanations regarding the student contract must be negotiated with the students, so there should be no fulmination when the students are announced as fail when they did not meet the requirements as stated within the student contracts.

Weekly task both written and online should be reported on time, students who incomplete the tasks may receive the opportunity to make up for the missing assignments before the final exam. If the students do not collect the tasks that have been given, the student may fail for the course by getting D for the subject. It can be re-evaluated while the mark is still marked as BL (not complete), but the student cannot take the remedy class due to the incomplete task. 
Another significant point that is mentioned in student contract relates to the student attendance that should be higher than $75 \%$, if the students cannot meet the requirement without acceptable excuse then they will receive E for Shokyuu Hyouki. Both significant points are commonly violated during Shokyuu Hyouki class; however, the consequence should be obtained. As a consequence, the result of this subject is quite low which is mostly caused by the violation of student contact. Other points that are mentioned in the contracts relate to general requirements such as dress code, late coming, and mark percentage.

The second to the seventh meetings on Shokyuu Hyouki are done through lecture class model which is basically similar to the previous semester learning model. Each week, students will discuss 2 chapters of Japanese Kanji while the evaluation is done weekly. On the first 50 minutes class, students receive quizzes and questions that relate to Kanji that have been learned. This model of learning is continued for six weeks, but the result shows a disappointing evaluation because of only few students in a small percentage that can complete the assignment and gain good marks.

Shokyuu Hyouki is a continuous course of Hyokui Nyuumon that introduce basic Kanji form. While on Shokyuu Hyouki, students are required to master more Kanji letters; so forcing them to remember 2 chapters of Kanji is common since the subject is the continuation of Kanji learning. However, in an actual case, the students still cannot memorize Kanji because the number of letters that they have to remember each week is excessive.

Mid-semester test or UTS is done as a written test, students are evaluated through their mastery in 12 chapters of Kanji. Unfortunately, their result is poor as only few students receive more than 80 . As a result, the continuation of the class is done by reducing the number of chapters that should be learned every week.

The implementation of blended learning model of Shokyuu Hyouki course is done after mid-semester examination on the tenth to the fifteenth meeting. In total, there are six meetings where the students can access the Kanji Hyoushi app freely through play store on mobile phone with the android operation. On ninth meeting, students are instructed to download the Kanji Hyoushi application on play store. However, only JLPT N1-N5 Japanese Test app is chosen because the standard achievement of Shokyuu Hyouki course is equal to N4, and this app consists of the entire chapters that are studied in Shokyuu Hyouki. In other words, JLPT N1-N5 not only supports the achievement standard for N4 but it also corresponds to the goals of Shokyuu Hyouki subject. Through this app, students do not only access the Kanji letters for N4, but they can also find the entire level from N1 to N5. The app does not only provide Kanji features, as it also consists of bunpou subject or" language structures", and moji goi for "words". Besides, it also supported with simulations of Japanese competency test that should be completed in a specific time limit.

Each part of the Kanji Hyoushi app has 10 questions to be answered, students know the right answer only after they complete the entire assignments. On every assignment, the student will be marked based on the right answer that they get from the test; the app is also supported with key answers if the question they answered is wrong. After a student completes each section of the quizzes, it will be marked as star which is ranged from one to five. Although students may fail in collecting the 5-star, they can retake the quiz until they receive full mark. When giving the lecture in front of the classes, lecturer instructs the students to gather 5 stars to achieve a perfect score, it should be reported to the lecturer every week as proof that the students have taken the daring class. This model allows the students to take the entire process of learning on app individually at home. 


\section{Observation}

During Shokyuu Hyouki course with the implementation of blended learning model, students experience two teaching models. The daring model is conducted by accessing the Kanji Hyoushi app as well as the lecture class model by the teacher. Every week, each student is given assignments to access Kanji exercises that are available on Kanji Hyoushi app; while in the classes, each student interacts with the lecture in face to face conversation. Each week, one chapter of Kanji is discussed, then the lecturer will observe students that work on their assessments.

To access the application is classified as homework that should be taken outside of the class, the lecturer will observe the students to access the application every week. At least 50 types of quizzes that are available on Kanji Hyoushi app and each segment of the quizzes have questions that are similar to N4 questions. The entire 50 quizzes are divided into 8 to 9 different categories that have to be completed every week. Every section that is answered by the students indicates their marks, while their weekly reports are used to observe the competence level of the students in mastering Kanji. Unfortunately, not all students are discipline in accessing the Kanji Hyoushi app, it is shown on the weekly reports on each section. However, the number of students who give reports every week is still greater than those who are not; discipline act of the students will affect the entire mark as it is agreed and written on student contract.

\section{Evaluation}

Evaluation toward Shokyuu Hyouki course is done through mid-semester test UTS as well as final test UAS, and lecturer that is done before the UTS will be evaluated through written Kanji test. Weekly evaluation is completed to measure the achievement of each student in mastering Kanji letters that were previously learned; and during UTS, students take the written text. Classes that are taken after the UTS are not required to be writtenly tested, because students only need to show their achievement on Kanji tests that are hinted by their full mark stars on 8 to 9 parts of the Kanji test each week.

In completing the final test, students must complete the written test that is available on the applications that should be done early. Students who get perfect score through the application does not need to take Kanji test. The test itself should be completed in a certain time limit; students are given 10 minutes to access 50 parts of the test on Kanji Hyoushi and every student must receive 5 starts on the test. Students that complete the test perfectly will automatically receive A for their mark, and they don't have to take a written test for Kanji course.

On the final test or UAS, six chapters of Kanji that had been learned in the previous weeks are tested on the class. The mark is determined by the accumulation of the text mark, the mid-semester exam, and assignments.

\section{Results and Discussion}

\section{Result of Learning Achievement}

On the previous years, Kanji was learned through lecture only; however, this traditional leaning system does not correspond to the target achievement of Shokyuu Hyouki course. It is proven as only few students who can pass the Japanese language competency test on N4 level, it shows that the learning achievement and Kanji mastery on N4 level is not possible trough lecture model.

As a consequence, blended learning model is introduced and implemented on Shokyuu Hyouki class. The combination of lecture and independent learning system through apps 
hopefully will help the students to master the entire Kanji on N4 level. It shows that the use of apps on the learning model is helpful to achieve the class target.

Japanese language competency test is done annually in West Sumatra, and it is usually conducted in November. Since the exam has not been placed this year, so the percentage of student who takes Shokyuu Hyouki course and passes the test cannot be estimated. Although the students have not taken the test, each test of the apps can be answered by the students even if the student has not learned the Kanji on the class yet.

N4 level is the first and the main target of the Shokyuu Hyouki achievement, it consists of the ability to read and write the Kanji. As the student reaches the first target it also means that student can also achieve the second to the fourth target easily; because their capability in reading and writing correspond to their ability to read the text, to write a text, and to translate the text from the Japanese language that is on N4 level. Besides, students can also attain soft skill ability through blended learning. Students indeed accessing the apps autonomously, at the same time the students are also given both responsibility and independence at the same time to complete each assignment; these targets cannot be achieved if the class is only done as a lecture.

\section{The Distribution of Final Mark}

Measuring the success of blended learning method is possible trough comparing the final mark distribution on Shokyuu Hyouki course on the current and the previous semesters. The following table describes the distribution of final marks on students who take Hyouki II (the name of course on the previous semester before being replaced)

Tabel 1. The Result of Hyouki II class on the previous semester

\begin{tabular}{|l|l|l|l|l|l|l|l|l|l|}
\hline Mark & A & A- & B+ & B & B- & C+ & C & D & E \\
\hline Precentage & $19.7 \%$ & $6.1 \%$ & $9.1 \%$ & $10.6 \%$ & $15.1 \%$ & $7.6 \%$ & $18.2 \%$ & $4.5 \%$ & $9.1 \%$ \\
\hline
\end{tabular}

This table is compared to the final marks which are achieved by students after taking Shokyuu Hyouki with blended learning method through the use of Kanji Hyoushi apps.

Tabel 2. The Result of Shokyuu Hyouki on current class

\begin{tabular}{|l|l|l|l|l|l|l|l|l|l|}
\hline Mark & A & A- & B+ & B & B- & C + & C & D & E \\
\hline Precentage & $28.1 \%$ & $8.8 \%$ & $14.7 \%$ & $10.3 \%$ & $5.8 \%$ & $7.3 \%$ & $5.8 \%$ & $5.8 \%$ & $20.5 \%$ \\
\hline
\end{tabular}

It shows a rise in percentage on the student result on the students marks especially on range $\mathrm{A}$ to $\mathrm{B}+$, while the students who receive $\mathrm{B}$ and $\mathrm{C}$ is decreased. Although the number of students who get $\mathrm{D}$ and $\mathrm{E}$ significantly increases, it is caused by students who do not complete their weekly assignments or meet the requirement of $75 \%$ attendance. It has been explained previously that students need to follow the contract that has been agreed and negotiated on the first meeting, the written points on the student contract are crucial in determining the final mark of each student.

The students who received D on their final marks is those who do not complete their assignments during the course. To overcome this problem, the students can request for BL form and complete all assignments that are given. However, students still do not complete the assessment before the deadline of BL form; as a result, students receive D for their final mark. A significant number of students that get $\mathrm{E}$ has resulted from their own negligence. Those who 
get $\mathrm{E}$ are students that do not meet the $75 \%$ requirement for attendance, as it is also explained on the contracts those who do not meet $75 \%$ for the attendance is considered failed. Students that get $\mathrm{E}$ cannot be reevaluated because the requirement for $\mathrm{BL}$ and remedial class is $75 \%$ attendance on class.

If the cause of low mark that comes from student negligence can be avoided, the result implies that blended learning method is successfully implemented on Shokyuu Hyouki course. As it is shown that students that get A straight are risen by $8.4 \%, \mathrm{~A}$ - around $2.7 \%$, $\mathrm{B}+$ for $5.6 \%$, while students that get B are decreased by $0.3 \%$ as well as $\mathrm{B}-$ for $9.3 \%, \mathrm{C}+$ for $0.3 \%$ and $\mathrm{C}$ by $12.4 \%$.

\section{Student Respond toward Learning Method Improvement}

Although blended learning method is implemented to Shokyuu Hyouki course for the first time, most students respond with positive reviews toward the use of Kanji Hyoushi app to support the class. The app is proven to help the student in memorizing Kanji letters which are considered as the hardest aspect on Japanese language compare to hiragana and katakana. The number of Kanji that should be memorized is a lot, white the writing and reading system on Kanji are complex.

The use of Kanji Hyoushi app help students to memorize Kanji letter trough the given test, it only needs internet access to download the app. The app does not only provide Kanji test but also other segments that are tested on the Japanese language competency test; besides, students can also measure their capability trough N1 to N5 level.

\section{Conclusion}

Shokyuu Hyouki is a compulsory subject for third-semester students at Japanese Department Andalas University. In past years, this subject had been named as Hyouki II before it is renamed as Shokyuu Hyouki to fit the current curriculum. Target achievements of Shokyuu Hyouki course include the mastery of N4 level of Kanji that is equivalent to their competence in reading and writing Kanji, understanding the Japanese text, and translating the Japanese text on N4 level. To measure student capability, Japanese language competency test is conducted; it consists of 5 different levels in which N5 is the lowest level that can be achieved and N1 as the highest.

The class was previously conducted as face to face lecture, but this model cannot be continued in Kanji learning because the current curriculum requires the students to pass N3 level. If the lecture model class is continued then the target achievement N3 is impossible to reach.

This research is a descriptive study as a form of true experimental by comparing the students on different benches; the comparison is done from bench 2017 class that took Hyouki II class with lecture model learning and 2018 class that took Shokyuu Hyouki class with blended learning method. The subject of this research is university students in their third semester on Japanese Department Andalas University. Blended learning model is done by combining lecture and online class trough Kanji Hyoushi app which is JLPT N1-N5 Japanese test.

The result shows that blended learning model has been successfully implemented on Shokyuu Hyouki course, it is proven by the increase of percentage on the students who receive $\mathrm{A}$ and $\mathrm{B}+$ compared to students of the previous year. A decrease occurs on the number of students that receive $\mathrm{B}$ and $\mathrm{C}$, while students with $\mathrm{D}$ and $\mathrm{E}$ are mostly caused by their own negligence on tasks as well as attendance that is less than $75 \%$. Through observation and 
interview, students imply that Kanji Hyoushi app helps them in memorizing Kanji letters; as a result, this learning model is positively rated by the students.

\section{References}

[1] Yanti, Martina Fitri. 2015. Analisis Perluasan Makna Kanji yang memiliki Bushu Tsuki, Nikuzuki, Funazuki. Jurnal Online Mahasiswa FKIP UNRI. Vol. 2

[2] Takamizawa. H. 2002. Hajimete no Nihongo Kyouiku no Nannatsu Dougu Shirizu 2 Kanji Jugyou no Tsukurikata Hen. Tokyo: Aruku Kabushiki Gaisha. p. 82

[3] Lalima dan Dangwal. 2017. Blended Learning: An Innovative Approach. Universal Journal of Education Research

[4] Sutedi. D. 2009. Penelitian Pendidikan Bahasa Jepang. Bandung: Humaniora. p. 58

[5] Nursyahidah, Farida.2007. Penelitian Eksperimen. Jurnal Academia.edu. Universitas Negeri Malang. p. 5 